\title{
A STEPWISE REGRESSION ANALYSIS ON UNDER-FIVE DIARRHOAEL MORBIDITY PREVALENCE IN NEKEMTE TOWN, WESTERN ETHIOPIA: MATERNAL CARE GIVING AND HYGIENE BEHAVIORAL DETERMINANTS
}

\section{Abstract}

\author{
Wondwossen Birke Eshete
}

\begin{abstract}
Objective: Various studies have addressed the relationship between maternal care giving behaviours including hygiene behaviours and the occurrence of diarrhoea in children. However, very few studies have done in Ethiopia in general and none exist in Nekemte town, western Ethiopia. Therefore, the present study aimed to estimate the prevalence of under-five diarrhoea morbidity in relation to mothers/care takers behaviours including hygiene behavioural determinants.

Methods: Community-based cross-sectional study was conducted in Nekemte town, western Ethiopia from October 15- November 26, 2007. 477 mothers/ care takers of index under-five children living in the households selected randomly from sub cities in the town formed the study population. Structured and pre-tested questionnaire was used to collect data. The data were entered into a computer, edited and analyzed using SPSS for windows version 12.01. Stepwise logistic regression model was used to calculate the Odds ratios and $95 \%$ confidence interval for the different risk factors was considered.

Results: From 477, 461 were participated in the study giving a response rate of $96.6 \%$. The mean ages of the respondents and the index children were about $32.4( \pm 8.8 \mathrm{SD})$ years and $25.27( \pm 15.16 \mathrm{SD})$ months respectively. Diarrhoea morbidity prevalence over a period of two weeks preceding the study was about $28.9 \%$. Although several maternal cares giving and hygiene-related risk factors showed significant association with diarrhoea morbidity on bivariate analysis, the use of cover material during drinking water transportation, faeces seen around the pit-hole and bottle feeding were the only significant variables on multivariate analysis. Conclusion: As diarrhoea morbidity was major problem among under-five children in Nekemte town, appropriate intervention programmes should be formulated focused on identified risk factors.
\end{abstract}

$\underline{\text { Key Words : Diarrhoea morbidity, Maternal care giving behaviors, Hygiene behaviors, Prevalence, and Under-five children }}$

\section{Introduction}

Diarrhoea contributes to an annual 3 million deaths in children under the age of five worldwide and diarrhoea-related illness and complications are associated with malnutrition, growth faltering, and compromised immunity $(1,2)$. The burden of diarrhoea morbidity lies largely in the developing world where water and living conditions remain poor. For example in Africa, a child experiences five episodes of diarrhoea per year, and 800,000 children die each year from diarrhoea and dehydration (3). A more recent estimate indicated the two-week period prevalence of diarrhoea in under-five children is about 30.6 and 17.7 percent in Ethiopia and Oromiya region respectively (4).

Different studies done in different parts of Ethiopia have also shown that diarrhoea incidence and prevalence is very high among under-five children. A community based study conducted in Keffa-Sheka Zone, southern Ethiopia, found a two-week childhood diarrhoea prevalence of 15 percent (5). Another study from Jimma town, southwest Ethiopia, showed a prevalence of 36.5 percent (6).

Interventions to improve hygiene behaviors, sanitation, and water quantity and quality can reduce allcause morbidity by $>20 \%$ (7) and hygiene interventions specifically were reported to reduce diarrhoea morbidity by nearly $45 \%$ (8). The World Bank has declared the promotion of improved hygiene to be the third most productive method for preventing diarrhoea-related morbidities (9). Different reports noted that, hand washing after defecating or handling babies' faeces and before preparing food, feeding children or eating are also crucial to reduce the transmission of diarrhoea germs. Washing with water alone is not enough. To remove faecal contamination,

Jimma University, Public Health Faculty, School of Environmental Health Sciences P.O.Box: 947, Telephone: Fixed line, +251-047-1128124; Mobil, +251-0911-548943, Fax: +251-047-

E-mail: wondwossenbirke@yahoo.com, Jimma, Ethiopia hands must be washed with an agent such as soap, mud or ashes which requires the hands to be rubbed together. To be on the safe side the provision of safe water sources and sanitation facilities is important. But constructing latrines and digging wells will have little effect on health unless people use these facilities, wash their hands and store drinking water hygienically in the home. Water may become unsafe at any point between collection and use. Clean water can easily become contaminated by dirty fingers or when it is poured in to a dirty container (10).

Many writers argued that, among the 2.6 billion people who currently lack adequate sanitation provision, many increase the health risks through their own lack of hygiene. Avoiding contact with fresh faeces and washing hands with soap or ash after defecation are simple hygiene measures that can have a major impact on disease transmission. Household and community cleanliness also reduce exposure to risks. Millions of the world's poorest people are exposed to infection through the way they earn their living (11).

To this effect, different studies showed that availability of improved water sources or latrine alone will not reduce diarrhoea morbidity, without a change in behaviour that affects hygiene practice (12). Even though the source is protected, water may be contaminated at or following collection, i.e. during transport and/or storage. Water stored in an uncovered container may be contaminated easily by pets, dirt, or other debris (13).

Different studies were conducted in Ethiopia on water- handling practices and sanitation behaviour. For example a study conducted by Desta (2003), unpublished source, at Agaro town showed that, $83 \%$ and $83.77 \%$ of the respondents use cover material during transport and store water at home respectively and $75.67 \%$ of the households practice dipping method to draw water from the container. Another unpublished study done by Mulugeta (1997) in Jimma town showed that, only 58\% of the respondents covers the collection container during transport to their house, $85 \%$ rinse/wash the container before collection and $52.2 \%$ dipping cup with handle and 
$42.5 \%$ with out handle to draw water from the container. Dirty utensils used to draw water from a storage container may also contaminate the water obtained from protected sources. A study revealed that the prevalence of diarrhoea was significantly higher in children from households where water is obtained from storage container by dipping than in those where water is obtained by pouring (8).

There are also studies done on the risk factors for diarrhoeal disease and have attempted to describe the relationship between parental behaviour and the occurrence of childhood diarrhoea. They suggested that maternal practices related to hygiene, breastfeeding, food preparation, and health care are important determinants of diarrhoeal disease incidence (12). In their study on breastfeeding and the occurrence of acute childhood diarrhoea, Ketsela et al (1991) found out that the risk of developing diarrhoeal disease in partially breastfed infants was five-times higher than that of infants exclusively on breast milk (14). Further more, it has been reported that there is a high chance of contamination, and greater risk of diarrhoea associated with bottle-feeding (9, 15).

Although, there exists a difference with their study findings the influence of improved water supply and sanitation factors on the prevalence of diarrhoeal diseases has been addressed in a number of studies. Despite of the aforementioned implications and the need for ongoing research, very few studies have focused on the influence of maternal and hygiene behaviours associated with prevalence of diarrhoea among under-five children in Ethiopia in general and none exist in Nekemte town, Western Ethiopia. In this study, therefore an attempt was made to assess the prevalence of diarrhoeal morbidity among under-five children and investigate the influences of the associated maternal care giving and hygiene behavioural risk factors in Nekemte town, Western Ethiopia.

\section{Methods}

A community-based analytical cross-sectional study was conducted in Nekemte town, East Wollega zone from October 15- November 26, 2007. East Wollega zone is one of the 17 zones in Oromiya Regional State located in the western part of the region at $331 \mathrm{~km}$ away from Addis Ababa. The study area, Nekemte town, is the capital city of the zone and it is administratively divided into 6 SubCities. According to the 2006 Federal CSA abstracts Nekemte's total population is approximated to 88,536 and with about 14,541 households (16). The total number of under-five children in the town is estimated to be 16,398 at the end of 2007 based on the assumption that $18 \%$ of the total population is under-five children (17).

The source population were all mothers/ care givers of index under-five children and under-five children living in the town prior to the survey. The study population was mothers/care givers of index under-five children and under-five children living in the selected households from randomly selected Sub-Cities in the town. If there were more than one under-five children in the same family, only one index child was selected by lottery method to collect information on child's health characteristics. Mothers/care givers of index under-five children who were mentally retarded or abnormal, critically ill and those who did not live at least six-months in the town prior to the survey were excluded.

The two-week period prevalence of diarrhoea among under-five children of the study area was not identified and studied before. Hence, the regional two-week period prevalence of diarrhoea among under-five children i.e., $17.7 \%$ was taken from the recent report of the Demographic and Health Survey (18) to calculate the sample size. Moreover, the flowing assumptions were considered: a design effect of 2 , desired precision $5 \%$ and 95\% confidence level and $10 \%$ for the anticipated none response rate. Accordingly, the total sample size was 434. The final sample size needed for the study was 477 .

Multi stage sampling procedure was employed. In the initial stage, three from six Sub-Cities were randomly selected using lottery method. Accordingly, 'BekeJama', 'BurqaJato', and 'Cheleleki' Sub-Cities were selected. Then, all households in the selected Sub-Cities were registered through a house-to-house survey by fifteen trained $10^{\text {th }}$ grade completed enumerators from October 15 - 312007 (to draw a sampling frame). Accordingly, a total of 5928 households of which, 1348, 2206, and 2374 households were from BekeJama, BurkaJato, and Cheleleki Sub-Cities, respectively were selected. The probability proportional to size allocation of households to each Sub-City was carried out based on the total number of selected households they have. Systematic random sampling (every $12^{\text {th }}$ households) from the selected households in the Sub-Cities was included for the study.

Data was collected using a structured questionnaire prepared by reviewing previously done similar studies and other materials on the topic. The questionnaire was translated into Afaan Oromo by fluent speaker of both languages to ensure its validity and consistency, and again back to English. Fifteen interviewers who have completed grade $10^{\text {th }}$ and above who are fluent in Afaan Oromo recruited and trained. Three supervisors from Nekemte Health centre were selected and trained. They were fully responsible to lead and handle the whole session of data collection process, and correct any problem along with the principal investigator.

Training was given for both interviewer and supervisors for 3 days before and after pre-test in the form of discussion by using the training guide that was developed by the principal investigator. Hence briefing on the general objectives of the study, discussing the contents of the questionnaires one by one and the type of information needed, any questions arising during data collection time; and discussions on how to maintain confidentiality and privacy were communicated. And 5\% of the questionnaires were pre-tested in another sub city with the same level in every aspects of basic infrastructure and socio-demographic characteristics in the study area. The result of the pre-test was used to correct some unclear ideas and statements. Moreover, the completed questionnaires were checked everyday after data collection for completeness, clarity and consistency by the supervisors and the principal investigator.

In the study, the occurrence of any episode of diarrhoea in a child two-week preceding the survey was 
considered to be the dependent (outcome) variable and maternal care giving behaviours, including water and sanitation related hygiene behaviors (such as hand washing and feeding practices; drinking water transportation, storage, drawing and treatment practices, and latrine and compound cleanliness) as exposure variables.

The collected data were edited, entered into a computer using SPSS version 12.01, and analyzed. Accordingly, the data were categorized and coded. The frequencies, measures of central tendencies and variations were obtained for each variable and displayed mainly on the tables and word expressions.

Bivariate analysis was also used to see the association between the explanatory and outcome variables. Logistic regression model was used to determine Odds ratio and $95 \%$ confidence interval for the different risk factors of diarrhoea and describe the strength of association between the selected study variables by controlling for the effect of possible confounders and prediction of population parameters. The final (multivariate analysis) model was ran by selecting only those that appeared to be statistically significant $(\mathrm{P}<0.05)$ in the bivariate analysis and reported as the result of this study.

Ethical clearance was obtained from the Ethical Committee of the Faculty of Public Health, Jimma University. Then the concerned officials in the zone at each level were communicated through formal letter from the School of Environmental Health Science, Faculty of Public Health of Jimma University. Informed verbal consent was obtained from the mothers of the children. Privacy and confidentiality were maintained during interview. Children who were found to be sick during the visits were advised to visit the nearby health institution.

\section{Results}

A total of 477 households with at least one underfive children were planned to participate in the study, out of which 461 study subjects were enrolled making a response rate of $96.6 \%$.

One hundred twenty four of the mothers/caretakers $(26.9 \%)$ were above 35 years of age while the majority, $270(58.6 \%)$ were in the age range of $25-35$ years. The mean age of the respondents was 32.4 years $( \pm 8.8 \mathrm{SD})$. The majority of mothers were married 395 (85.7\%), Orthodox 196(42.5\%) by religion followed by Protestant $183(39.7 \%)$ and Oromo by ethnic group 347 (75.3\%). Regarding occupation, 314 (68.1\%) were housewives, $63(13.7 \%)$ and $83(18.0 \%)$ were government employee and private gainful respectively. $58(12.6 \%)$ mothers were illiterate. Of the $403(87.4 \%)$ mothers who had formal education, $196(42.5 \%)$ and 207 (44.9\%) attended some primary and secondary education, respectively. The mean household size of the study population was 5.5 ( $\pm 2.0 \mathrm{SD})$ persons. About $263(57 \%)$ of the households had less than five persons in their families. There was only one under-five child in $383(83 \%)$ households, and only $77(16.1 \%)$ and $1(0.2 \%)$ households had two and three under-five child, respectively (Table 1).
Table 1. Socio- economic and demographic characteristics of the respondents, Nekemte town, February 2008

\begin{tabular}{|c|c|c|c|}
\hline Variable & $\begin{array}{l}\text { Response } \\
\text { category }\end{array}$ & $\begin{array}{l}\text { Frequency } \\
(\mathrm{n}=461)\end{array}$ & $\%$ \\
\hline \multirow{3}{*}{$\begin{array}{l}\text { Total persons in } \\
\mathrm{HH}^{*}\end{array}$} & $<5$ & 263 & 57 \\
\hline & $5-8$ & 164 & 35.6 \\
\hline & $>8$ & 34 & 7.4 \\
\hline \multirow{2}{*}{$\begin{array}{l}\text { No of under } \\
\text { children in } \mathrm{HH}\end{array}$} & One & 383 & 83.1 \\
\hline & Two \& above & 78 & 16.9 \\
\hline \multirow[t]{4}{*}{ Age of mother } & $<18$ & 8 & 1.7 \\
\hline & $18-24$ & 59 & 12.8 \\
\hline & $25-35$ & 270 & 58.6 \\
\hline & $<35$ & 124 & 26.9 \\
\hline \multirow[t]{4}{*}{ Marital status } & Single & 10 & 2.2 \\
\hline & Married & 395 & 85.7 \\
\hline & Divorced & 33 & 7.2 \\
\hline & Widow & 23 & 5 \\
\hline \multirow[t]{4}{*}{ Religion } & Orthodox & 196 & 42.5 \\
\hline & Protestant & 183 & 39.7 \\
\hline & Muslim & 80 & 17.4 \\
\hline & Others & 2 & 0.4 \\
\hline \multirow[t]{4}{*}{ Ethnicity } & Oromo & 347 & 75.3 \\
\hline & Amhara & 103 & 22.3 \\
\hline & Garage & 8 & 1.7 \\
\hline & Other & 3 & 0.7 \\
\hline \multirow[t]{3}{*}{ Maternal Education } & Illiterate & 58 & 12.6 \\
\hline & Elementary & 196 & 42.5 \\
\hline & $\begin{array}{l}\text { Secondary \& } \\
\text { Above }\end{array}$ & 207 & 44.9 \\
\hline \multirow{4}{*}{$\begin{array}{l}\text { Occupation } \\
\text { mother }\end{array}$} & Housewife & 314 & 68.1 \\
\hline & $\begin{array}{l}\text { Government } \\
\text { employee }\end{array}$ & 63 & 13.7 \\
\hline & $\begin{array}{l}\text { Private gainful } \\
\text { work }\end{array}$ & 83 & 18 \\
\hline & Other & 1 & 0.2 \\
\hline \multirow{3}{*}{$\begin{array}{l}\text { Average monthly } \\
\text { income of } \mathrm{HH}\end{array}$} & $<500$ & 171 & 37.1 \\
\hline & $501-1000$ & 186 & 40.3 \\
\hline & $>1000$ & 104 & 22.6 \\
\hline
\end{tabular}

The age ranges of the children included in this study were from 0-6, 7-11, 12-23, 24-35 and 36-59 and in each range there was a total of $43(9.3 \%), 37(8.1 \%), 132$ $(28.6 \%), \quad 121 \quad(26.2 \%)$ and $128 \quad(27.8 \%)$ children respectively. The mean age of the index children thus found to be about $25.27( \pm 15.16 \mathrm{SD})$ months. Moreover, $260(56.4 \%)$ and $201(43.6 \%)$ of the children were male and female by sex respectively. As to the current breast feeding status of the child, the majority $277(60.1 \%)$ of the children were non-breast feed, $138(29.9 \%)$ were partially breast feed and only $46(10 \%)$ of the index children were exclusively breastfeeding (Table 2 ).

Out of the total 412 mothers/caretakers who started supplementary feeding for their children 264(64.1\%) started before the child reached 6 months, where as some $148(35.9 \%)$ started after the age of 6 and above months. As far as the method they used to feed their child is considered, 195(47.3\%) mothers used cup and spoon, $221(53.6 \%)$ used their hands, and $137(33.3 \%)$ bottle to feed their child (Table 2).

It is interesting to note that out of 461 respondents the majority $340(73.8 \%)$ do not treat their drinking water while about $121(26.25 \%)$ do treat their drinking water at household level prior to consumption by using either boiling, adding chlorine, or strain through a cloth. 
The majority of the respondents, $407(88.3 \%)$ used a covered container during transportation of the drinking water from the sources and only a small proportion $54(11.7 \%)$ did not cover their drinking water container during transportation to their home. Furthermore, almost all, 434(94.1\%) of the respondents reported that they had a separate storage container and cover their storage container in the home 435(94.3\%). Also the respondents were asked for their method of water drawn from the storage container, and the majority $371(80.5 \%)$ responded that they draw water by pouring and $90(19.5 \%)$ draw water from the storage container by dipping (Table 2 ).

Table 2. Maternal Care Giving and Hygiene-Related Behaviour Characteristic $s$ of the study households, Nekemte town, February, 2008

\begin{tabular}{|c|c|c|c|}
\hline Variable & Response category & $\begin{array}{l}\text { Frequency } \\
(\mathrm{n}=461)\end{array}$ & $\%$ \\
\hline \multirow[t]{3}{*}{$\begin{array}{l}\text { Current breastfeeding } \\
\text { status of the chills }\end{array}$} & $\begin{array}{l}\text { Exclusive } \\
\text { breastfeeding }\end{array}$ & 46 & 10 \\
\hline & Partial breastfeeding & 138 & 29.0 \\
\hline & Not breastfeeding & 277 & 60.1 \\
\hline \multirow{2}{*}{$\begin{array}{l}\text { Supplementary feeding } \\
\text { (months) }\end{array}$} & $<6$ & 264 & 64.1 \\
\hline & $>6$ & 148 & 35.9 \\
\hline \multirow{3}{*}{$\begin{array}{l}\text { Methods used in } \\
\text { supplemtary feeding }\end{array}$} & Hand & 221 & 53.6 \\
\hline & Cup \& spoon & 195 & 47.3 \\
\hline & Bottle & 137 & 33.3 \\
\hline \multirow{2}{*}{$\begin{array}{l}\text { Drinking } \\
\text { transportation }\end{array}$} & In a cover container & 407 & 88.3 \\
\hline & $\begin{array}{l}\text { In } \\
\text { container }\end{array}$ & 54 & 11.7 \\
\hline \multirow{2}{*}{$\begin{array}{l}\text { Home drinking water } \\
\text { treatment }\end{array}$} & Yes & 121 & 26.2 \\
\hline & No & 340 & 73.8 \\
\hline $\begin{array}{l}\text { Separate storage } \\
\text { container for drinking } \\
\text { water }\end{array}$ & Yes & 27 & 5.9 \\
\hline $\begin{array}{l}\text { Cover water storage } \\
\text { container }\end{array}$ & No & 435 & 94.3 \\
\hline \multirow{2}{*}{$\begin{array}{l}\text { Method of drawing } \\
\text { water }\end{array}$} & By pouring & 371 & 80.5 \\
\hline & By dipping & 90 & 19.5 \\
\hline \multirow{2}{*}{$\begin{array}{l}\text { A separate ca/cup for } \\
\text { dipping }(\mathrm{N}=90)\end{array}$} & Yes & 63 & 70 \\
\hline & No & 27 & 30 \\
\hline \multirow{2}{*}{$\begin{array}{l}\text { Doest the can/cup have } \\
\text { handle }\end{array}$} & Yes & 54 & 60 \\
\hline & No & 36 & 40 \\
\hline \multirow{4}{*}{$\begin{array}{l}\text { How often do you wash } \\
\text { your hands }\end{array}$} & After defecation & 281 & 61 \\
\hline & $\begin{array}{l}\text { Before preparing } \\
\text { child's food }\end{array}$ & 104 & 22.6 \\
\hline & $\begin{array}{l}\text { After cleansing } \\
\text { child's faeces }\end{array}$ & 106 & 23 \\
\hline & After eating & 157 & 34.1 \\
\hline \multirow{3}{*}{$\begin{array}{l}\text { Cleansing materials } \\
\text { used to wash hands }\end{array}$} & Soap & 313 & 67.9 \\
\hline & Ash & 2 & 0.4 \\
\hline & Only water & 146 & 31.7 \\
\hline $\begin{array}{l}\text { Faeces seen around the } \\
\text { pit-hole/slab/floor }\end{array}$ & Yes & 154 & 36 \\
\hline of latrine $(\mathrm{N}=423)$ & No & 269 & 64 \\
\hline \multirow{2}{*}{$\begin{array}{l}\text { Faeces seen in the } \\
\text { compound }\end{array}$} & Yes & 111 & 24.3 \\
\hline & No & 350 & 75.7 \\
\hline
\end{tabular}

As indicated in Table 2, mothers/caretakers were asked about their hand washing practice. Accordingly, $281(61 \%), 104(22.6 \%), 106(23 \%)$ and $157(34.1 \%)$ of the respondents responded that they often used to wash their hands after defecation, before preparing child's food, after cleansing child's faeces and after eating, respectively. About 423 (91.8\%) of the study households were responded that they either had privately owned or shared latrine facility and a proportion of $38(8.2 \%)$ households do not have the facility. From these 423 households with latrine facility, faeces were seen around the pit-hole/slab/floor of latrine of 154 (36\%) households.

Upon further questioning to identify the history of diarrhoea, 329(71.4\%), 65(14.1\%) and 133(28.9\%) study participants had reported that their child had a history of diarrhoea during their life time, survey time and in the past two weeks periods respectively. Out of the two week report of diarrhoeal history, $118(77.6 \%)$ mentioned that a child exhibit a watery type of diarrhoea and 34(22.4\%) had bloody \& mucus diarrhoeal type.

Bivariate and multivariate logistic regression was used to identify the characteristics that differentiated the child who had diarrhoea during the two week period prior to the survey from those who do not had diarrhoea, and the dichotomous variable is defined as $1=$ child who had diarrhoea: $0=$ the child who did not have diarrhoea during the two week period. Coefficients were expressed as crude and adjusted OR relative to the referent category.

In the Bivariate analysis, a number of risk factors emerged as significant predictors of under-five childhood diarrhoeal morbidity. These include presence or absence of the cover of drinking water container during transportation to the house, home drinking water treatment,

the presence of faeces around the pit-hole $(\mathrm{P}<0.001)$, cover of the storage container in the house, faeces seen in the compound, hand wash practice after cleansing child's faeces $(\mathrm{P}<0.05)$, breast feeding status of the child $(\mathrm{P}<0.05)$ and the use of bottle to feed the child $(\mathrm{P}<0.001)$ were found to be significantly associated with under-five childhood diarrhoeal morbidity (Table 3 ).

Multivariate logistic regression model was employed to evaluate associations between factors and dichotomous variables designed to measure maternal care giving behaviors, including hygiene behaviors risk factors and under-five childhood morbidity in the last two-weeks prior to survey. In the model, variables which were found to be associated significantly in a bivariate analysis were re-evaluated independently controlling for other potential confounders. Hence, most of the variables disappear and condition of drinking water transportation to the house from the source, the presence of faeces around the pithole, and the use of bottle to feed the child were remained to be independent risk factors/predictors of under-five childhood diarrhoeal morbidity. Children from households who claimed to transport their drinking water using covered container had about $87 \%$ less likely to have diarrhoea than children from households who transports their drinking water using uncovered container, [OR: $0.13,95 \% \mathrm{CI}(0.02,0.85)]$. Again children from those households in which faeces were observed around the pit-hole/on the slab had about three times more likely to had diarrhoea compared to those children from houses in which faeces had not observed around the pit-hole[OR : $3.13,95 \%$ CI $(1.04,9.45)]$. Bottle feeding had also found to be about three times more likelihood of increased risk of getting diarrhoea than those children who did not used bottle feeding method [OR: 3.16, 95\% CI $(1.04,9.64)$ ]. 
Table 3 Bivariate Analysis: Variables significantly associated with under-five childhood diarrhoeal morbidity, Nekemte town, February, 2008.

\begin{tabular}{|c|c|c|c|c|}
\hline \multirow{2}{*}{ Variables } & \multicolumn{2}{|c|}{ Diarrhoea } & \multirow{2}{*}{ Crude OR (95\% CI) } & \multirow{2}{*}{ P-Value } \\
\hline & Yes $(\%)$ & No (\%) & & \\
\hline \multicolumn{5}{|l|}{ Breast feeding status } \\
\hline Exclusively breast feed & $6(13)$ & $40(87)$ & 1.00 & \\
\hline Partially breast feed & $45(32.6)$ & $93(67.4)$ & $3.22(1.27,8.16)$ & 0.014 \\
\hline Not breast feed & $82(29.6)$ & $195(70.4)$ & $2.80(1.14,6.86)$ & 0.024 \\
\hline \multicolumn{5}{|l|}{ Drinking water transportation } \\
\hline In covered container & $99(24.3)$ & $308(75.7)$ & $0.19(0.10,0.34)$ & 0.000 \\
\hline In uncovered container & $34(63)$ & $20(37)$ & 1.00 & \\
\hline \multicolumn{5}{|c|}{$\begin{array}{l}\text { Home drinking water treatment (strain } \\
\text { through a cloth) }\end{array}$} \\
\hline Yes & $11(45)$ & $9(45)$ & 1.00 & \\
\hline No & $30(30)$ & $70(70)$ & $0.35(0.13,0.093)$ & 0.036 \\
\hline \multicolumn{5}{|l|}{ Storage container in home } \\
\hline Have cover & $118(27.2)$ & $316(72.8)$ & $0.27(0.12,0.61)$ & 0.002 \\
\hline Do not have cover & $15(57.7)$ & $11(42.3)$ & 1.00 & \\
\hline \multicolumn{5}{|l|}{ Faeces around pit-hole/slab } \\
\hline Yes & $70(45)$ & $84(55)$ & 1.00 & \\
\hline No & $52(19)$ & $217(81)$ & $0.29(0.19,0.45)$ & 0.000 \\
\hline \multicolumn{5}{|l|}{ Faeces seen in the compound } \\
\hline Yes & $42(37.8)$ & $69(62.2)$ & 1.00 & \\
\hline No & $91(26)$ & $259(74)$ & $0.58(0.37,0.91)$ & 0.017 \\
\hline \multicolumn{5}{|c|}{ Hand wash after cleansing child's faeces? } \\
\hline Yes & $20(18.9)$ & $86(81.1)$ & 1.00 & \\
\hline No & $112(31.6)$ & $242(68.4)$ & $1.99(1.17,3.40)$ & 0.012 \\
\hline \multicolumn{5}{|l|}{ Bottle feeding } \\
\hline Yes & $58(42.3)$ & $79(57.7)$ & 1.00 & \\
\hline No & $69(24.2)$ & $216(75.8)$ & $0.44(0.28,0.67)$ & 0.000 \\
\hline
\end{tabular}

\section{Discussion}

A number of studies revealed that poor maternal care giving behaviors, including hygiene behaviors related to water and sanitation contribute to the leading killers of children under-five, including diarrhoea disease (12). Interventions to improve hygiene behaviors were reported to reduce diarrhoea morbidity by nearly $45 \%$ (8).

This study used a representative sample of households with at least one under-five child in Nekemte town to determine maternal care giving behaviors, including hygiene behaviors associated with the twoweek period prevalence of childhood diarrhoeal morbidity. The study presents findings from community based analytical cross-sectional survey of the study area.

The two-week period prevalence of childhood diarrhoea morbidity in this study was $28.9 \%$. This finding is almost inconsistent with the study done in different parts of the south-western Ethiopia which was about $33.7 \%$ and $36.5 \%$ in Manna district and Jimma town, respectively $(19,6)$. But the finding is not in agreement with the one reported from Keffa-Sheka Zone, southern Ethiopia which showed about $15 \%$ of two- week period prevalence of diarrhoeal morbidity (5). The difference might be attributable to the difference in the socio demographic characteristics of study households.

As to the water handling practice, the findings of this study showed that about $88.3 \%$ of the respondents reported that they cover their material during transport to house, 94\% reported that they used a separate storage container and the container have a cover. In line with this, this finding is in comparable with the findings of thesis done by Desta (2003), unpublished, in Agaro which showed $83 \%$ and $83.7 \%$, respectively. In the present study, it has been found that about $19.5 \%$ of the respondents claimed that they used dipping method to draw water from the storage container which is lower than the findings reported by Desta (2003), which sowed about 52.2\% used dipping method. Even though, significance association was not observed in this study 
between method of drawing water from storage container and diarrhoeal morbidity, another study revealed that the prevalence of diarrhoea was significantly higher in children from households where water is obtained from storage container by dipping than in those where water is obtained by pouring (5).

On the other hand, our study showed a significant association between drinking water transportation to the house and under-five childhood diarrhoeal morbidity. Children from households who claimed transport their drinking water using uncovered container had about $87 \%$ more likely to have diarrhoea than children from households who transports their drinking water using covered container, [OR: $0.13,95 \% \mathrm{CI}(0.02,0.85)]$. This might be attributable to because of the fact that, even though the source is protected, water may be contaminated at or following collection, i.e. during transport and/or storage. Water stored in an uncovered container may be contaminated easily by pets, dirt, or other debris (13).

The presence or absence of faeces around the pithole or on the slab was another independent predictor of under-five childhood diarrhoeal morbidity identified in this study. Children from those households in which faeces were observed around the pit-hole/on the slab had about three times more likely to had diarrhoea than those children from houses in which faeces had not observed around the pit-hole[OR : 3.13, 95\%CI (1.04,9.45)]. Consistent with our findings other study also reported that the presence of excreta around pit hole showed strong association with under-five childhood diarrhoeal morbidity (15). This is an important implication that the mere presence of latrine facility does not have a great contribution for prevention of excreta-related disease but it is the proper utilization that had a vital importance.

In this study, significant association was observed between method of bottle feeding and diarrhoeal morbidity. Children who were on bottle feeding had about three times more likely to have diarrhoea than those children who did not used bottle feeding [OR: 3.16, $95 \%$ CI $(1.04,9.64)]$. This is inconsistent with the study findings reported by Getaneh et al (1997) and Van Derslice et al (1994) which found out that that there is a high chance of contamination and greater risk of diarrhoea associated with bottle-feeding $(6,15)$.

Even though they disappeared in multivariate analysis, breast feeding status of the child and hand washing after cleansing child's faeces were significantly associated with diarrhoeal morbidity in bivariate analysis. Different literatures also revealed that maternal practices related to hygiene, breastfeeding, food preparation, and health care are important determinants of diarrhoeal disease incidence (12,6, and 15).

\section{Acknowledgments}

I am grateful to Jimma University for its financial and material support to undertake the study. I would also like to express my gratitude to Nekemte City Administration and Municipality, the data collectors and the study participants as a whole.

\section{References}

1. Lanata CF, Black RE. Diarrhoeal diseases. In: Semba RD, Bloem MW (eds) Nutrition and Health in Developing Countries. Totowa: Humana Press, 2001. Nutrition and Health in Developing Countries. Totowa: Humana Press, 2001.
Bern C, Martines J, Zoysa Ide \& Glass RI. The magnitude of the global problem of diarrhoeal disease: a ten- year update. Bull. WHO 1992; 70(6): 705-714.

3. Woldemichael G. Diarrhoeal morbidity among young children in Eritrea: Environmental and socioeconomic determinants. J Health Popul Nutr. 2001 Jun; 19(2): 83-90.

4. Ethiopia Demographic and Health Survey (DHS). Central Statistics Authority \& ORC Marco. Addis Ababa, Ethiopia and Calverton, Maryland, USA, 2005.

5. Teklemariam S, Getaneh $T$ \& Bekele F. Environmental determinants of diarrhoea morbidity in under-five children. Keffa-Sheka Zone. Southwest Ethiopia. Ethiop. Med. J. 2000; 38(1): 27-34.

6. Getaneh T. Assefa A, Taddesse Z. Diarrhoea morbidity in urban area of South-west Ethiopia. East Afr. Med. J. 1997; 74(8): 491-494.

7. Aiello AE, Larson EL. What is the evidence for a causal link between hygiene and infections? Lancet Infect Dis 2002; 2:103-10.[CrossRef][ISI][Medline]

8. Fewtrell L, Kaufmann RB, Way $D$ et al. Water, sanitation, and hygiene interventions to reduce diarrhoea in less developed countries: a systematic review and meta-analysis. Lancet Infect Dis 2005; 5:42 52.[CrossRef][ISI][Medline]

9. Martines J, Phillips M, Feacham RGA. Diarrhoeal diseases. In: Jameson DT, Mosley WH, Measham AR, Bobadillo JL (eds). Disease Control Priorities in Developing Countries. Oxford: Oxford University Press, 1993.

10. Dialogue on Diarrhoea. Hygienic habits in the home: No-54 Sep- Nov. 1993

11. IRC International Water and Sanitation Centre, Sanitation for All? June 2007, pp.10, UK

12. Mock NB, Sellers TA, Abdoh AA \& Franklin RR. Socioeconomic, environmental, demographic and behavioral factors associated with the occurrence of diarrhoea in young children. Soc. Sci. Med. 1993; 36(6): 807816.

13. Asnake M. Water handling practices and their association with childhood diarrhoea. MPH Thesis. AAU; 1991

14. Ketsela T. Knowledge and practice of mothers/caretakers towards diarrhoea and its treatment in rural communities in Ethiopia. Eth. Med. J.1991; 29(4)

15. Van Derslice J, Popkin B \& Briscoe J. Drinking water quality, sanitation and breastfeeding: their interactive effects on infant health. Bull. of WHO. 1994; 72(4): 589-601.

16. Central Statistical Authority (CSA) Statistical Abstract of Federal Democratic Republic of Ethiopia, January 2006, Addis Ababa, Ethiopia.pp.50

17. Federal Ministry of Health of Ethiopia (FMOH) Health and Health related indicators. 2005 Addis Ababa, pp.22

18. Ethiopia Demographic and health survey (DHS). Central Statistics Authority \& ORC Marco. Addis Ababa, Ethiopia and Calverton, Maryland, USA, 2005.

19. Kaba M \& Ayele F. Ethnographic study of diarrhoeal disease among underfive children in Mana District, Jimma Zone, and Southwest Ethiopia. Ethiop. J. Health Dev. 2000; 14(1):77-83 